\title{
On Theory and Practice
}

\author{
Scott Simpson, reply by Nikos Salingaros
}

In response to "The Rise of the Architectural Cult" (Vol. 5, No. 1).

To the editors:

In his review of Making Dystopia, Nikos Salingaros raises some good points, but misses several others. One that stands out is the presumption that there exists some sort of high priesthood in the architectural profession that is devoted to advancing the principles of the International Style, and that it has the power to exile those who do not follow its precepts, barring them from meaningful participation in the higher echelons of the profession. While it is true that the work of such architects as Le Corbusier, Walter Gropius, and Ludwig Mies van der Rohe has been enormously influential in shaping modern architecture, a quick scan of the most noteworthy design being done today (including projects by many Pritzker Prize winners) makes it clear that the International Style is no longer dominant.

A key factor that is often overlooked by critics is that the architect, no matter how talented, must operate within parameters that are established by the owner. This includes the site, program, budget, and schedule. Owners are also hugely influential in the design process itself, since they are presented with a range of possible options and provide guidance as to the direction that the design will take. In fact, most world-class practitioners will say that the best projects result from a true collaboration between the designer and the client. Even Mies admitted this, most famously in his design for the iconic Farnsworth house. The list of influential owners is a long one and includes such names as Eli Broad of Los Angeles, who has endowed projects ranging from museums to research institutes, as well as a private residence in collaboration with Frank Gehry. J. Irwin Miller went even further, providing funds for the city of Columbus, Indiana, to hire world-class architects-including Eero Saarinen, I. M. Pei, and Robert Venturi-for many municipal structures from schools to fire stations. Design talent is certainly relevant, but nothing happens without a client.

As to the pursuit of design orthodoxy, consider such current design luminaries as Norman Foster, Bjarke
Ingels, Renzo Piano, and Moshe Safdie. Each one has done highly regarded work internationally, but none follows a stylistic playbook. Foster's projects include both the so-called Gherkin in London as well as the Hearst Tower in New York-both iconic tall buildings that could not be more different. Ingels is known for playful form-making-no two projects are ever the same. Piano has done marvelous work for many cultural institutions, but his museums in Manhattan and Boston take entirely different approaches. Safdie burst onto the scene at a young age based on his work for the groundbreaking Habitat housing project in Montreal, but his later work looks nothing like it at all.

Furthermore, the use of computer-aided design has greatly expanded what is possible, and so we are seeing wildly creative shapes and forms that would have been impossible to produce just a decade ago. Leading examples can be found in the work of Zaha Hadid, now deceased, and Gehry, whose museum in Bilbao helped revitalize an entire city. Neither designer could be accused of being an advocate for the International Style. The recent trend toward sustainable design has also had a notable effect on form-making, as architects and engineers are becoming increasingly adept at producing zero-carbon and zero-emissions buildings, which require a very different approach to design and construction.

In fact, things are changing so fast in the world of design that academia has a very hard time keeping up. Most professors of architecture are theory-based rather than practice-based, so they are ill-equipped to guide the next generation of design leaders in how to navigate what is rapidly becoming a very different profession. What makes this particularly difficult is that the curriculum for accredited schools of architecture is highly regulated, and in order to maintain their standing to grant qualified degrees, schools must follow the script. There is simply too much to learn and not enough time to keep up with the pace of innovation. Hence, newly minted graduates must forge their own paths.

The bottom line is that it takes more than just an architect to make a building. It also requires clients, engineers, consultants, contractors, and skilled tradespeople. Design- 
ing and constructing the built environment is very much a social act, which is why architecture is such a great storytelling device: it reflects who we are as a civilization. If you want to know what people really value, just look at what they build. Architecture speaks volumes.

\section{Scott Simpson}

\section{Nikos Salingaros replies:}

The comment by Scott Simpson, a respected architect and author, raises questions that are typical concerns of the profession today. This gives me a chance to focus on what the architectural mainstream is likely to understand from the recent exchange of views published in Inference. There are three points upon which I entirely agree with Simpson:

1. Work by the currently famous crop of award-winning starchitects does not look altogether like the industrial modernism that arose after the 1920s.

2. Academia is hardly keeping up with progress in architectural practice and implementation, and is tied by an antiquated accreditation process.

3. Every design project is severely constrained by the client's design brief, budget, site, and wishes.

Let me begin by addressing the first point. Although Simpson disagrees that "there exists some sort of high priesthood in the architectural profession that is devoted to advancing the principles of the International Style," it is my presumption that the cult of power does indeed exist. Though it is not devoted to advancing only the International Style of Bauhaus modernism, it is all a game of style nevertheless. And, while contemporary styles do flaunt a very different look, they still fail to satisfy most of the criteria used to classify the architectural expressions that are good for human health and wellbeing. Those are summarized in detail below.

The second point holds the key to how we shape architects so that they, in turn, will shape a better future for humanity. I like Simpson's statement about our current education system: "There is simply too much to learn and not enough time to keep up with the pace of innovation. Hence, newly minted graduates must forge their own paths."

I cannot agree more! But perhaps Simpson has in mind a different direction than I do of what new path our students and young architects must pursue. I believe that today, aspiring architects need to master a body of knowledge that is, almost without exception, missing from school curricula. They should learn how the human body adapts to its environment and how architecture creates either a positive or negative catalyst for life processes. ${ }^{1}$ Students need to break out of the established order going way back to the Bauhaus, which tends to channel their creativity into images irrelevant to our biology. ${ }^{2}$
Indeed, a group of architects and educators is currently engaged in a radical rethinking of architectural education. ${ }^{3}$ This movement is global, since the greatest contradiction between obscenely expensive and wasteful skyscrapers and self-built squatter settlements occurs in the developing world. It is also significant that the impetus for reform comes from outside the usual academic channels.

Our understanding of architecture has changed fundamentally and is not going back to its old yardsticks based on dogma. The unprecedented message published in Inference-conveyed through essays by myself, James Stevens Curl, Miguel Córdova Ramírez, Martin Horáček, Michael Mehaffy, and Malcolm Millais ${ }^{4}$-is that two groups of people use two entirely distinct sets of criteria for judging whether architecture is good or not. In such a situation, there can be no agreement between the two opposing camps, and it is pointless to debate whose opinion is better. Resolution can come only from a scientific analysis of those basic criteria, and Inference is doing the world a tremendous favor by hosting this discussion.

Tests have recently been formulated to evaluate the human qualities of architecture in an objective manner. Architecture that is "good for you" as judged on scientific evidence needs to take into account new diagnostic tools and standards. Dominant architectural culture doggedly ignores this body of research.

1. Human evolution took place in complex visual environments, so that our sensory information-processing system is set up to recognize specific types of organized complexity. ${ }^{5}$ Symmetry provides meaning to architecture-but only those special symmetries that create a healing environment for the user. ${ }^{6}$

2. The beneficial effects of biophilia can be estimated using ten criteria that guarantee a visceral connection with the human body and mind. Sunlight: preferably from several directions; Color: variety and combinations of hues; Gravity: balance and equilibrium about the vertical axis; Fractals: things occurring on nested scales; Curves: on small, medium, and large scales; Detail: meant to attract the eye; Water: to be both heard and seen; Life: living plants, animals, and other people; Representations of nature: naturalistic ornament, realistic paintings, reliefs, and figurative sculptures, including face-like structures; Organized complexity: intricate yet coherent designs, extending to symmetries of abstract face-like structures. ${ }^{7}$

3. Eye-scanning experiments, and software that simulates eye-scanning, will distinguish among engaging facades that attract our unconscious attention in the first 3 to 5 seconds of viewing, versus disengaging facades that are simply not seen and might as well not be there. ${ }^{8}$ Promoting buildings that disengage violates human nature. 
These are paradigm-changing ways of looking at architecture. They serve to discredit many of the design techniques and unnatural values the profession inherited from the fashionable radicalism of the 1920s. Nobody bothered to assess the consequences those typologies had on the people who actually inhabited them-until now, one century later. It is a wonder that deficient ways of thinking about how to shape the built environment survived for so long. Today we are at the flash point when false assumptions underpinning architectural theory are finally invalidated.

Built architecture is defined by the market, which is manipulated by design ideology, giant money interests, and propaganda. The profession is socialized to accept the party line, where everything is supposedly going just fine. Those who are arguing for radical change do not have the media access of established organizations; hence our voice remains unheard. We are counting on the chance that society might care enough about science to listen to the message these essays communicate. But that is a vain hope.

For this reason, I fundamentally diverge from Simpson's relaxed complacency about the current situation, regardless of what else we agree upon. I believe the profession to veer close to malpractice because of its continued and stubborn ignorance of the science of life. Humanity's future depends, in part, on ethical and intelligent architects realizing the enormity of the chasm separating official practice from people's biological needs.

The third point listed at the top of this essay is that the client makes the final decisions. Whoever pays usually, though not always, gets what they want. What Simpson says about our society is sadly true: "Architecture is such a great storytelling device: it reflects who we are as a civilization. If you want to know what people really value, just look at what they build."

At this moment in time, our iconic architecture proclaims us to be an insensitive, manipulated herd driven by megalomania. The design arrogance of so-called starchitects is not only tolerated but rewarded. We worship technology and the alien styles it makes possible, while foolishly ignoring science. It should be the other way around: science should inform design. Image-based design of signature buildings should not decide which science it is lucrative to adopt.

I reject the descriptors Simpson employs to evaluate famous architects practicing today. The clichés "wildly creative shapes and forms," "groundbreaking," "marvelous work," "iconic tall buildings," "highly regarded work internationally," "current design luminaries," "world-class practitioners," and "the most noteworthy design being done today" mean nothing to me, although I am well aware that they are generally accepted within the profession. The press does bandy those words about, which helps these architects gain even more commissions. But there is absolutely no convergence on human-centered designs. Their buildings lack the qualities that science proves are necessary to provide healing environments. All I see is individuals working to deplete the earth's raw materials and energy resources for the speculative gain of multinationals and rapacious developers.

As a LEED AP (Leadership in Energy and Environmental Design Accredited Professional), Simpson buys into the narrative that the architecture-industrial complex is helping with sustainability. I don't. Overwhelming data casts doubt on the optimistic declarations that zero-carbon and zero-emissions buildings that follow industrial modernism make any serious difference. ${ }^{9}$

I find very little architecture sensitive to human biology among major prize winners. This is not personal taste, but the result of applying science. True, dominant architectural culture is outraged that a segment of the population ignores what the elite considers the profession's highest recent achievements. Yet this result was inevitable. For decades, architectural high culture has been at odds with what ordinary people prefer, an uncomfortable fact buried by media justification pointing to the "ignorance" of the masses. ${ }^{10}$ Curiously, it is not the masses that have finally revolted, but the normally reserved and tranquil scientists.

Finally, let me counter Simpson's skepticism that the "high priesthood ... has the power to exile those who do not follow its precepts, barring them from meaningful participation in the higher echelons of the profession." Among successful, talented architects from the previous generation that the cult erased from common memory are Julian Abele, Geoffrey Bawa, Paul Bonatz, Hassan Fathy, Edwin Lutyens, Julia Morgan, Jože Plečnik, Friedrich Scholer, and so many others. Practitioners alive today pointedly ignored by the media include Christopher Alexander and winners of the Driehaus Architecture Prize. And that's only for starters. What happened, and is happening, is disreputable and tragic.

Architecture is not going to advance if we continue to shut our eyes to the wrong direction it has taken, and especially its autarchic and repressive aspects. Nonstop hostilities against anything traditional-or merely what is not part of approved industrial-modernist and avantgarde styles-has conditioned architects toward hatred and intolerance. The remedy must be to reject denial, retrenchment, and the continued impulse to respond to past misdeeds by superficial whitewashing.

\section{Scott Simpson is an award-winning architect, a Richard Upjohn Fellow of the American Institute of Architects, and a Senior Fellow of the Design Futures Council.}

Nikos Salingaros is Professor of Mathematics at the University of Texas at San Antonio.

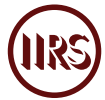


1. Christopher Alexander, The Timeless Way of Building (New York: Oxford University Press, 1979); Christopher Alexander, The Nature of Order, Books 1-4 (Berkeley: Center for Environmental Structure, 2001-2005).

2. Nikos Salingaros, "What Architectural Education Does to Would-Be Architects," Common Edge, June 8, 2017.

3. Nikos Salingaros and Kenneth Masden, "Architecture in the Making: Intelligence-Based Design," in In Pursuit of a Living Architecture: Continuing Christopher Alexander's Quest for a Humane and Sustainable Building Culture, ed. Kyriakos Pontikis and Yodan Rofè (Champaign: Common Ground Publishing, 2016), 30-49; Two Series of Essays on Architectural Education, ed. Nikos Salingaros (New Delhi: Architexturez, 2020).

4. Miguel Córdova Ramírez, "A False Promise of Progress," Inference 5, no. 2 (2020); Martin Horáček, "Architects as Physicians," Inference 5, no. 2 (2020); Michael Mehaffy, “An Obsolete Ideology," Inference 5, no. 2 (2020); and Malcolm Millais, "The Origins of Architectural Barbarism," Inference 5, no. 2 (2020).

5. Ann Sussman and Justin Hollander, Cognitive Architecture (New York: Routledge, 2015); Donald Ruggles, Beauty, Neuroscience \& Architecture (Denver: Fibonacci Press, 2018).

6. Nikos Salingaros, "Symmetry Gives Meaning to Architecture," Symmetry: Culture and Science 31, no. 3 (forthcoming 2020), special issue on Geometry and Architecture, ed. Vilmos Katona, 331-61.

7. Nikos Salingaros, "The Biophilic Healing Index Predicts
Effects of the Built Environment on Our Wellbeing," Journal of Biourbanism 8, no. 1 (2019): 13-34; Nikos Salingaros, "Neuroscience Experiments to Verify the Geometry of Healing Environments: Proposing a Biophilic Healing Index of Design and Architecture," in Urban Experience and Design: Contemporary Perspectives on Improving the Public Realm, ed. Justin Hollander and Ann Sussman (New York and London: Routledge, 2020), 58-72.

8. Ann Sussman and Janice Ward, "Eye-Tracking Boston City Hall to Better Understand Human Perception and the Architectural Experience," New Design Ideas 3, no. 1 (2019): 53-59; Nikos Salingaros and Ann Sussman, "Biometric Pilot-Studies Reveal the Arrangement and Shape of Windows on a Traditional Façade to Be Implicitly 'Engaging', whereas Contemporary Façades Are Not," Urban Science 4, no. 2 (2020): 1-19, doi:10.3390/urbansci4020026.

9. Michael Mehaffy and Nikos Salingaros, "Why Green Architecture Hardly Ever Deserves the Name," ArchDaily, July 3, 2013. Reprinted as Chapter 2 of Design for a Living Planet (Portland: Sustasis Press, 2015).

10. Michael Mehaffy and Nikos Salingaros, "Building Tomorrow's Heritage. III. Correcting Architectural Myopia," Preservation Leadership Forum, National Trust for Historic Preservation (September 26, 2019); Michael Mehaffy and Nikos Salingaros, "Building Tomorrow's Heritage. IV. Making Places for All, by All," Preservation Leadership Forum, National Trust for Historic Preservation (May 20, 2020).

Published on September 28, 2020

https://inference-review.com/letter/on-theory-and-practice 